\title{
O EMPREGO DA LEGITIMAÇÃO FUNDIÁRIA SOBRE AS ÁREAS DE TITULARIDADE PRIVADA: UM EXAME ACERCA DA PROPORCIONALIDADE DO ARTIGO 23 DA LEI 13.465/17
}

\author{
Antônio Carlos Apolinário de Souza Cardoso ${ }^{1}$ \\ Roberto Apolinário de Souza Cardoso 2
}

Resumo: A Regularização Fundiária Urbana-Reurb possui duas finalidades: a) formalizar as relações de posse e propriedade; e b) efetivar o acesso ao direito à moradia. A Lei 13.465/17 trouxe a legitimação fundiária. Este instrumento, para parte da doutrina (ROSENVALD, 2017), representa ofensa à garantia institucional do direito de propriedade. A pergunta que se pretende responder é: em que medida a legitimação fundiária se adequada aos direitos fundamentais. A hipótese levantada é de que nos casos de Reurb de interesse social a aplicação do instrumento se apoia no direito à moradia. Utilizou-se como metodologia a pesquisa bibliográfica, legislativa e documental.

Palavras-chave: legitimação fundiária, regularização fundiária, proporcionalidade, propriedade, direito à moradia.

\section{THE USE OF LAND LEGITIMIZATION OVER PRIVATELY OWNED AREAS: AN EXAMINATION OF THE PROPORTIONALITY OF ARTICLE 23 OF LAW 13.465 / 17}

\begin{abstract}
The Urban-Reurb Land Use Regularization has two purposes: a) to formalize relations of ownership and ownership; and b) effective access to the right to housing. Law 13.465 / 17 brought land ownership legitimacy. This instrument, for part of the doctrine (ROSENVALD, 2017), represents an offense against the institutional guarantee of property rights. The question to be answered is: to what extent does land ownership legitimize fundamental rights. The hypothesis raised is that in cases of Reurb of social interest the application of the instrument relies on the right to housing. Bibliographical, legislative and documentary research was used as methodology.
\end{abstract}

Key words: Land legitimization, land regularization, proportionality, property, right to housing.

\section{INTRODUÇÃO}

A regularização fundiária dos espaços informais é uma demanda presente na sociedade brasileira atual, que contou com profícua produção legislativa nas últimas duas décadas (FERNANDES, 2010).

\footnotetext{
1 Mestrando da Linha de Pesquisa Direitos Humanos e Meio Ambiente, do PPGD-UFPA. Contato: acapolinarioscardoso@gmail.com. Fone: (91) 98810-3744.

${ }^{2}$ Possui graduação em Direito pelo Centro Universitário do Estado do Pará (2011). Formado no LL.m em Direito Empresarial pela Fundação Getúlio Vargas Rio de Janeiro.
}

Revista Brasileira de Direito Civil em Perspectiva | e-ISSN: 2526-0243| Porto Alegre | v. 4 | n. 2 | 
Atualmente, o assunto é regulado pela Lei 13.465/17, que trouxe inovações significativas frente às antecessoras, dentre elas, um novo instrumento, a legitimação fundiária.

A legitimação fundiária traz aspectos próprios, inova no ordenamento por sua abrangência e alcance inéditos, posto que, diferentemente de seus congêneres, incide sobre bens privados e públicos; afastando-se, inclusive, de outras formas legais de aquisição da propriedade, como a usucapião, pois: i) não se submete a lapsos temporais expressos; ii) não exige a observância a verificação da boa-fé e da justiça da posse; e iii) sua declaração é competência administrativa, das Prefeituras.

Ante as peculiaridades elencadas na regulação da legitimação fundiária surgem questionamentos sobre sua conformidade ao regime jurídico constitucional brasileiro (ROSENVALD, 2017).

Este estudo tem por objeto examinar o instrumento da legitimação fundiária, sua relação com a promoção da regularização fundiária e averiguar sua adequação ao direito brasileiro, notadamente sua consonância com a eficácia dos direitos fundamentais.

O objetivo geral deste estudo é averiguar em que medida o instrumento da legitimação fundiária se adequa com a tutela dos direitos fundamentais. Os objetivos específicos são: a) apresentar a disciplina legal da legitimação fundiária; b) verificar a compatibilidade da aplicação da legitimação fundiária áreas privadas.

O problema da pesquisa é: em que medida a legitimação fundiária se harmoniza com o Direito brasileiro? A hipótese levantada é a de que legitimação fundiária, quando empregada nas hipóteses de regularização fundiária de interesse social, constitui importante instrumento de acesso ao direito à moradia, por isso aplicável ainda sobre áreas particulares.

A análise foi conduzida a partir de pesquisa bibliográfica, legislativa e documental.

Além da introdução, este artigo é dividido em três seções. A primeira apresenta considerações introdutórias sobre a regularização fundiária no Brasil, em especial, o seu desenvolvimento legislativo. A segunda aborda a regulação legal da legitimação fundiária a partir da decomposição dos elementos do artigo 23 da Lei 13.465/17. Já a última seção se 
dedica ao exame da proporcionalidade da aplicação da legitimação fundiária nas hipóteses de regularização sobre áreas de propriedade privada. Em sede de considerações finais, conclui-se pela constitucionalidade da legitimação fundiária sobre áreas particulares quando a ação de Regularização Fundiária Urbana-Reurb for na modalidade de interesse social, bem como são indicadas alternativas legais para os casos de regularização de interesse específico sobre áreas privadas.

\section{A REGULARIZAÇÃO FUNDIÁRIA URBANA NO BRASIL}

A população brasileira, em um dos movimentos socioterritoriais mais rápidos que se tem notícia, mais precisamente na segunda metade do século $\mathrm{XX}$, passou de predominantemente rural para majoritariamente urbana (ROLNIK, 2006, p. 1).

A questão da moradia no Brasil, e nos demais países da periferia capitalista, possui questões peculiares, próprias da realidade do terceiro mundo, como exemplo a deficiente regulação estatal sobre o espaço urbano e o reduzido alcance do mercado residencial (MARICATO, 2010, p. 8).

Nos países em desenvolvimento, diferentemente das cidades dos países centrais do capitalismo (MARICATO, 2010, p. 8), não houve o Estado do bem estar social. Por isso, em tais locais, práticas especulativas e a apropriação da infraestrutura urbana por grupos privilegiados tiveram maior êxito que nas cidades dos Estados Unidos, Inglaterra e França, por exemplo; nas urbes do terceiro mundo, prevaleceram a segregação espacial e a informalidade urbana, exemplificando a máxima de que entre desiguais a lei liberta e a liberdade oprime.

Por tais fatores, explica Fernandes (2010, p. 179), com base na realidade brasileira que: “[...] historicamente, a informalidade passou a ser a única opção de produção da moradia nas cidades para grande parcela da população.”. Neste sentido, estima-se que no Brasil haja em torno de 11,4 milhões de pessoas vivendo em assentamentos (FAO/SEAD, 2017).

Somado a isso, além dos problemas decorrentes da exclusão social, como a habitação precária e a favelização, no Brasil a situação fundiária é caótica, há número elevado de habitações de baixo e alto padrão aquisitivo situadas em áreas de proteção ambiental ou em áreas de propriedade pública, predomina a indefinição da titularidade de terras, os limites das

Revista Brasileira de Direito Civil em Perspectiva | e-ISSN: 2526-0243| Porto Alegre | v. 4 | n. 2 |

p. 102-119 | Jul/Dez. 2018 
propriedades não raro são imprecisos, inexiste sistema de cadastro capaz de subsidiar o sistema de registro de propriedade; situação que denota uma débil governança fundiária no Brasil e prejudica, entre outras coisas, o mercado de terras (FAO/SEAD, 2017).

O desenvolvimento do mercado de terras tem sido apontado como uma importante fonte de ampliação de recursos públicos e, até mesmo, instrumento de combate à pobreza (DE SOTO, 2001) além e uma exigência do Banco Mundial para o repasse de recursos (FAO/SEAD, 2017). Sobre este ponto, explica Fernandes (2007):

[...] em alguns casos, o Banco Mundial, para liberação de recursos tem imposto a
formulação e implementação de políticas de regularização fundiária como condição
para a liberação de recursos. Há, contudo, pelo menos uma distinção fundamental
entre a campanha da ONU e as políticas do Banco Mundial. Enquanto a
ONU/Habitat está buscando o reconhecimento do direito social de moradia, o Banco
Mundial está explicitamente defendendo o direito individual de propriedade e a
homogeneização dos sistemas jurídicos nacionais, dentre outras razões, para
remover os obstáculos à circulaçãa global do capital imobiliário internacional.

É verdade que o Brasil busca, há algumas décadas, sanar as fragilidades habitacionais e fundiárias $^{3}$ na área urbana e rural, entretanto, as pressões internas pelo direito social à habitação (art. $6^{\circ} \mathrm{CF}$ ) e as do capital nacional e internacional, pela promoção do mercado de terras, tem sido as maiores influências sobre a produção legislativa interna.

Atualmente, a regularização de imóveis urbanos é disciplinada pela Lei 13.465/17, em seu título II. Diferentemente da Lei 11.977/09, o atual diploma não trouxe uma definição de regularização fundiária ${ }^{4}$, hoje intitulada de Reurb, no entanto, os artigos $9^{\circ}$ e $10^{\circ}$, respectivamente, trouxeram: os elementos multidisciplinares que devem ser objeto da Reurb

\footnotetext{
${ }^{3}$ Podem ser citados os seguintes antecedentes legislativos acerca da disciplina normativa sobre a regularização fundiária urbana no Brasil: Decreto lei $\mathrm{n}^{\circ} 58$ de 1937 (primeiro diploma a regular o parcelamento do solo); Lei 6.977/79 (Lei do parcelamento do solo urbano); Lei 9.785/99 (alterou a Lei de parcelamento do solo, trouxe tratamento especial aos assentamentos populares regularizados no âmbito de ações públicas locais); Emenda constitucional $\mathrm{n}^{\circ} 26$ de 2000 (definiu a moradia como direito social); Lei 10.257/01 (Estatuto da cidade); Lei 10.931/04 (instituiu a gratuidade do primeiro registro decorrente de regularização fundiária); Lei 11.481/07 (define mecanismos de regularização para terras da União); Lei 11.952 (regularização fundiária das terras localizadas na Amazônia legal - Programa terra legal); Lei 11.977/09 (dedicou capítulo à regularização fundiária de assentamentos informais urbanos); MP 759/16 (que revogou o capítulo relativo à regularização fundiária da Lei 11.977/09 e foi convertida na Lei 13.465/17 - diploma vigente sobre a regularização fundiária).

${ }^{4}$ A definição de regularização fundiária era encontrada no art. 46 da Lei 11.977/09: "Art. 46: A regularização fundiária consiste no conjunto de medidas jurídicas, urbanísticas, ambientais e sociais que visam à regularização de assentamentos irregulares e à titulação de seus ocupantes, de modo a garantir o direito social à moradia, o pleno desenvolvimento das funções sociais da propriedade urbana e o direito ao meio ambiente ecologicamente equilibrado.".
}

Revista Brasileira de Direito Civil em Perspectiva | e-ISSN: 2526-0243| Porto Alegre | v. 4 | n. 2 |

p. $109-112$ | Jul/Dez. 2018 
(art. $9^{\circ}$, caput), os princípios a serem observados (art. $\left.9^{\circ}, \S 1^{\circ}\right)$ e os objetivos da Reurb (art. $\left.10^{\circ}\right)$.

Pela conformação de seus princípios, marcada pela convivência de objetivos de cunho social e econômico, como: os princípios da sustentabilidade econômica e social assim como a previsão do objetivo de "promover a integração social e a geração de emprego e renda", percebe-se que a legislação tem no equilíbrio entre os interesses sociais ${ }^{5}$ e econômicos ${ }^{6}$ uma de suas características mais evidentes.

Coerente com os princípios e objetivos que conformam a regulação da Regularização Fundiária Urbana-Reurb, o procedimento da Reurb compreende duas modalidades: a) Reurb de interesse social (Reurb-S), voltada aos núcleos urbanos informais ocupados predominantemente por população de baixa renda; e b) Reurb de interesse específico (ReurbE) aplicável aos núcleos urbanos informais ocupados por população não qualificada como de baixa renda. O art. 13 da Lei 13.465/17 regula o tema:

Art. 13. A Reurb compreende duas modalidades:

I - Reurb de Interesse Social (Reurb-S) - regularização fundiária aplicável aos núcleos urbanos informais ocupados predominantemente por população de baixa renda, assim declarados em ato do Poder Executivo municipal; e

II - Reurb de Interesse Específico (Reurb-E) - regularização fundiária aplicável aos núcleos urbanos informais ocupados por população não qualificada na hipótese de que trata o inciso I deste artigo.

A Lei 13.465/17 trouxe diferenças para as Reurbs de interesse social, entre elas o registro do projeto de regularização em ato único (art. 17), a imposição ao poder público do custeio do projeto de regularização fundiária, a determinação para que as Prefeituras

\footnotetext{
${ }^{5}$ Direito social à habitação e urbanização de áreas desprovidas de infraestrutura pública (equipamentos públicos, saneamento básico e etc).

${ }^{6}$ Formalização dos direitos reais a partir do efetivo registro do direito, delimitação e localização da propriedade de forma a incorporar a propriedade imobiliária ao mercado de terras e possibilitar sua utilização com instrumento para empréstimos bancários. Neste sentido, explica Reydon et al (FAO/SEAD, 2017): “[...] é inegável reconhecer que, ainda que o modelo proposto por de Soto tenha inúmeras falhas, certamente a segurança jurídica ocasionada pela legitimação da posse, titulação e, consequentemente, a configuração do direito de propriedade podem gerar uma alavancagem no mercado de terras, além de outros benefícios socioambientais.".
} 
implantem a infraestrutura essencial e arquem com os ônus de sua manutenção (arts. 33, I e $37)$.

Dito isso, percebe-se que a regularização fundiária no Brasil possui uma dupla finalidade: i) promover o direito social à habitação (moradia digna); e, ii) reduzir as situações de informalidade da propriedade que dificultam o desenvolvimento do mercado de terras.

Portanto, presentes duas diferentes ordens de interesse na regulação da Reurb, torna-se natural a criação de procedimentos diferentes para as distintos interesses contemplados pelas ações de regularização fundiária urbana.

A Lei 13.465/17, em que pese o acerto de determinadas críticas ${ }^{7}$, trouxe: a simplificação de $\operatorname{procedimentos}^{8}$, ampliação de $\operatorname{conceitos}^{9}$ e a modificação do regime de alguns instrumentos utilizados na regularização fundiária, como a demarcação urbanística $^{10}$ e a legitimação da posse ${ }^{11}$, além de criar novos instrumentos - usucapião extrajudicial (art. 216-A da Lei 6.015/73) e a legitimação fundiária.

Passadas as considerações acerca do regime jurídico da regularização fundiária, bem como a apresentação dos distintos interesses que conformam sua regulação legal passamos à análise do instrumento da legitimação fundiária.

\section{ANÁLISE DA DISCIPLINA LEGAL DA LEGITIMAÇÃO FUNDIÁRIA}

\footnotetext{
${ }^{7}$ Para um ponto de vista crítico sobre o atual regramento da regularização fundiária urbana ver: VANIN, F., HERMANY, R.. Análise crítica das mudanças promovidas pela Medida Provisória n. 759/2016 na regularização fundiária do Brasil / Critical analysis of changes promoted by Provisional Measure n. 759/2016 in the land regulation in Brazil. Revista de Direito da Cidade, Local de publicação (editar no plugin de tradução o arquivo da citação ABNT), 9, abr. 2017. Disponível em: < publicacoes.uerj.br/index.php/rdc/article/view/27233 >. Acesso em: 20 Jan. 2018

${ }^{8}$ Como exemplos: tornou facultativo o emprego da demarcação urbanística (art. 19); delegou ao Município a competência para declarar, por ato próprio, a faixa de renda que compreende como baixa para enquadramento na Reurb-S, de forma a possibilitar o ente fazê-lo de acordo com sua realidade sócio econômica (art. 13, I); facilitou o procedimento do registro imobiliário com: a previsão do registro da Certidão de Regularização Fundiária-CRF (art. 41), a relativização do princípio da especialidade (art. 46) e simplificou o procedimento de notificações sob responsabilidade do registrador imobiliário $\left(\S 2^{\circ}\right.$ do art. 46) além de fixar prazos para a qualificação e registro CRF (art. 44 caput e $\S 5^{\circ}$ ), entre outras.

${ }^{9}$ Pela conceituação de núcleo urbano (art. 11, I) os Municípios passaram a poder efetuar Reurb sobre área "qualificada ou inscrita como rural" (art. 11, I, parte final), permitindo a ação municipal sobre área, até o momento da edição da Lei, submetida ao controle da União pelo Instituto Nacional de Colonização e Reforma Agrária-INCRA, a evitar maiores burocracias e prestigiando a autonomia municipal.

${ }^{10}$ Hoje facultativa (art. 19).

${ }^{11}$ Não mais se condiciona a prévia demarcação urbanística.
}

Revista Brasileira de Direito Civil em Perspectiva | e-ISSN: 2526-0243| Porto Alegre | v. 4 | n. 2 |

p. $109-112$ | Jul/Dez. 2018 
Como dito na seção anterior, a Lei 13.465/17 inovou frente à Lei $11.977 / 09$ no que dispõe a regularização fundiária urbana, sendo a legitimação fundiária uma de suas novidades. O conceito do novo instrumento é trazido pelo artigo 23 da Lei 13.465/17:

Art. 23. A legitimação fundiária constitui forma originária de aquisição do direito real de propriedade conferido por ato do poder público, exclusivamente no âmbito da Reurb, àquele que detiver em área pública ou possuir em área privada, como sua, unidade imobiliária com destinação urbana, integrante de núcleo urbano informal consolidado existente em 22 de dezembro de 2016.

A partir da análise do conceito legal acima, o estudo será dividido da seguinte maneira: a) forma originária de aquisição do direito real de propriedade; b) direito real de propriedade conferido por ato do poder público; c) aplicação exclusiva no âmbito da Reurb; d) incidência sobre hipóteses de detenção de área pública ou em posse sobre área privada; e) objeto de aplicação: unidade imobiliária com destinação urbana, integrante de núcleo urbano informal; e f) termo final para o seu reconhecimento: consolidado existente em 22 de dezembro de 2016.

Por aquisição originária da propriedade entende-se aquela que é feita de forma não negocial, onde o beneficiário adquire a titularidade do bem de forma independente da vontade do antigo adquirente, trata-se, portanto, de aquisição de direito novo, despido de eventuais vícios ou obrigações que por ventura gravaram a coisa.

Sobre conceito “aquisição originária” explica Loureiro (2011) em comentários sobre a usucapião:

É o modo originário de aquisição da propriedade, pois não há relação pessoal entre
um precedente e um subsequente, não constituindo este direito o pressuposto
daquele, muito menos lhe determinado a existência, as qualidades e a extensão. São
efeitos do fato de aquisição ser o título originário: não haver necessidade de
recolhimento do imposto de transmissão quando do registro da sentença [...]; o título
ingressar no registro independentemente de registro anterior, ou seja, constituir
exceção ao princípio da continuidade e mitigação da especialidade registrarias; os
direitos reais limitados e eventuais defeitos que gravam ou viciam a propriedade não
se transmitem ao usucapiente; e, caso resolúvel a propriedade, o implemento da
condição não resolver a propriedade plena adquirida pelo usucapiente; constituir
esplêndido instrumento jurídico; sanar os vícios de propriedade defeituosa adquirida
a título derivado.

Embora a simples menção à natureza originária da forma de aquisição da propriedade bastasse para a aquisição do direito de forma livre e desembaraçada, o legislador quis ressaltar 
este aspecto com as disposições dos parágrafos $2^{\circ}$ e $3^{\circ}$ do artigo 23 , a fim de apagar qualquer dúvida sobre a independência do direito conferido pelo poder público.

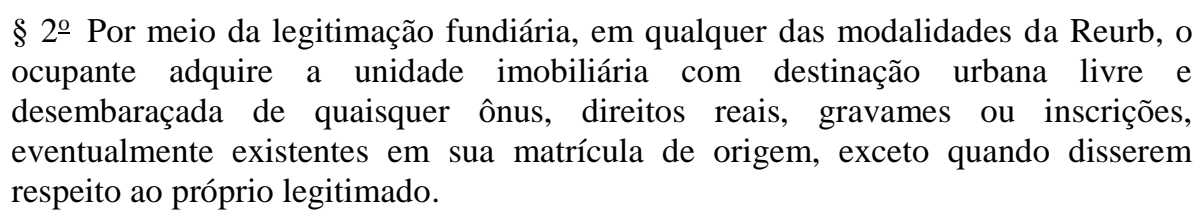

§ 3ำ Deverão ser transportadas as inscrições, as indisponibilidades ou os gravames existentes no registro da área maior originária para as matrículas das unidades imobiliárias que não houverem sido adquiridas por legitimação fundiária.

O direito será conferido pelo poder público mediante ato administrativo. Trata-se de hipótese de reconhecimento extrajudicial/administrativo da propriedade. Dessa maneira, basta que o beneficiário e o poder concedente atendam aos requisitos legais constantes no caput do artigo 23 , bem como àqueles presentes para a modalidade de Reurb aplicada (art. $23, \S 1^{\circ}$ ), para que o Poder Executivo possa reconhecer a propriedade do beneficiado sobre a unidade imobiliária.

Exclusivamente no âmbito da Reurb significa que salvo nas hipóteses de regularização fundiária urbana, não será possível o emprego da legitimação fundiária.

Um dos aspectos mais originais da legitimação fundiária é a possibilidade de sua utilização tanto em áreas privadas quanto em áreas públicas, ao menos nos casos de Reurb-S $\left(\operatorname{art} .23, \S 4^{\circ}\right)$.

A legitimação fundiária, aparentemente, relativiza a regra da imprescritibilidade dos imóveis públicos (art. 183, § 3º $\mathrm{CF}$ e art. 191, parágrafo único, $\mathrm{CF}$ ). No entanto, esse ponto de vista deve ser superado, pois enquanto a prescrição aquisitiva ocorre à revelia do antigo proprietário e/ou contra sua vontade; a legitimação fundiária se assemelha neste ponto à doação, posto que pressupõe a manifestação de vontade da administração, Prefeitura, concedente.

Outrossim, a aplicação da legitimação fundiária sobre imóveis públicos é restrita às hipóteses de Reurb-S, ou seja, somente será aplicada nas hipóteses em que a Administração estará agindo ao encontro do interesse público, promoção do acesso à moradia (art. $6^{\circ} \mathrm{CF}$ ).

Revista Brasileira de Direito Civil em Perspectiva | e-ISSN: 2526-0243| Porto Alegre | v. 4 | n. 2 |

p. $109-112$ | Jul/Dez. 2018 
No que diz respeito à aplicação da legitimação fundiária sobre imóveis particulares, este tema será analisado na próxima seção e em sede de considerações finais vista sua importância para este estudo.

O campo de aplicação da legitimação fundiária são as unidades imobiliárias com destinação urbana localizadas em um núcleo urbano informal. O conceito legal de núcleo urbano informal é informado pelo inciso I do art. 11 da Lei 13.465/17:

I - núcleo urbano: assentamento humano, com uso e características urbanas, constituído por unidades imobiliárias de área inferior à fração mínima de parcelamento prevista na Lei no 5.868, de 12 de dezembro de 1972, independentemente da propriedade do solo, ainda que situado em área qualificada ou inscrita como rural;

Por sua vez, o conceito de núcleo urbano passou a englobar não só as áreas urbanas e de expansão urbana, mas também as áreas rurais com destinação urbana, portanto, a Lei 13.465/17 abandonou o critério da localização para delimitação de sua aplicação.

Dessa forma, as ações de regularização fundiária urbana agora podem ser aplicadas mesmo em áreas localizadas na zona rural, desde que estas assumam características urbanas. Então, parece-nos possível a aplicação da legitimação fundiária em imóveis localizados fora da zona urbana ou de expansão urbana, desde que o núcleo onde se encontrem possua características urbanas.

Outro aspecto digno de nota, acerca do regramento legal da legitimação fundiária é que o legislador corretamente empregou os termos "detiver" e "possuir", posto que a correção na terminologia jurídica evita equívocos ou dúvidas hermenêuticas na aplicação do instituto.

O possuidor é aquele que "[...] tem de fato o exercício, pleno ou não, de algum dos poderes inerentes à propriedade" (art. $1.196 \mathrm{CC}$ ), enquanto o detentor é identificado pelas características do possuidor, com a diferença de que é juridicamente impedido de assumir a condição de possuidor e usufruir os benefícios decorrentes do exercício da posse (posse ad usucapionem e a indenização pelas benfeitorias praticadas), explicam Chaves e Rosenvald (2012):

Enquanto Savigny concebia-a na hipótese de ausência de animus domini por parte daquele que detém o poder físico sobre a coisa, Ihering abstraiu sua noção de qualquer elemento psíquico, diferenciando o detentor do possuidor pela regulamentação do direito objetivo.

Revista Brasileira de Direito Civil em Perspectiva | e-ISSN: 2526-0243| Porto Alegre | v. 4 | n. 2

p. 102-119 | Jul/Dez. 2018 
Essa distinção é importante, pois predomina que não há posse para os bens públicos, mas tão somente, detenção. Eis a posição que prevalece nos Tribunais brasileiros:

PROCESSUAL CIVIL E ADMINISTRATIVO. OFENSA AO ART. 1.022 DO
CPC/2015 NÃO CONFIGURADA. REINTEGRAÇÃO DE POSSE. OCUPAÇÃO
DE ÁREA PÚBLICA POR PARTICULARES. CONSTRUÇÃO. BENFEITORIAS.
INDENIZAÇÃO. IMPOSSIBILIDADE. 1. No que se refere à alegada afronta ao
disposto no art. 1.022 do CPC/2015, o julgado recorrido não padece de omissão,
porquanto decidiu fundamentadamente a quaestio trazida à sua análise, não podendo
ser considerado nulo tão somente porque contrário aos interesses da parte. 2. A
jurisprudência do STJ é firme no sentido de que, configurada a ocupação indevida
de bem público, não há falar em posse, mas em mera detenção, de natureza precária,
o que afasta o direito à indenização por benfeitorias. 3. Recurso Especial não
conhecido. (REsp 1701620/RS, Rel. Ministro HERMAN BENJAMIN, SEGUNDA
TURMA, julgado em 05/12/2017, DJe 19/12/2017)

O legislador estipulou ainda um limite temporal para aplicação da legitimação fundiária: a consolidação do núcleo urbano informal até 22 de dezembro de 2016; determinação harmônica com o art. $9^{\circ}, \S 2^{\circ}$ : “A Reurb promovida mediante legitimação fundiária somente poderá ser aplicada para os núcleos urbanos informais comprovadamente existentes, na forma desta Lei, até 22 de dezembro de 2016.”.

A data de 22 de dezembro de 2016 tem razão de existir, pois foi esse o dia em que entrou em vigor a Medida Provisória 759 de 2016, que deu origem a presente legislação.

A necessidade de estipular uma data limite para a utilização do instrumento em estudo guarda relação com a finalidade perseguida pela Reurb, que não é outra, senão a integração dos núcleos informais à cidade formal.

Isso porque, como explicado, a legitimação fundiária inova em diversos aspectos frente o direito positivo brasileiro, entre eles: i) permite o reconhecimento administrativo da propriedade; ii) não condiciona a aquisição da propriedade a duração da posse e iii) o reconhecimento de aquisição de bem público sem submissão às formalidades do art. 17 da Lei 8.666/93; são peculiaridades do instrumento estudado que se justificam apenas nas hipóteses de relevância social que envolvem a regularização fundiária urbana, e que, por essa excepcionalidade, não devem essas regras excepcionais serem aplicadas em situações ocorridas após a data limite sob pena de representarem indevido estímulo ao desrespeito das regras administrativas, urbanísticas, civis e ambientais. 
Por fim, esclarece o legislador, no artigo 24 da Lei 13.465/17, que a legitimação fundiária pode ser aplicada nas hipóteses de regularização previstas na Lei 11.977/09 para conferir propriedade aos ocupantes:

Art. 24. Nos casos de regularização fundiária urbana previstos na Lei no 11.952 , de 25 de junho de 2009, os Municípios poderão utilizar a legitimação fundiária e demais instrumentos previstos nesta Lei para conferir propriedade aos ocupantes.

\title{
2.1 Aspectos controversos sobre a aplicação da legitimação fundiária
}

Em que pese o caráter social e desburocratizante ${ }^{12}$ do qual é dotado o instrumento da legitimação fundiária, alguns aspectos acerca de sua regulação e potencial aplicação necessitam maior desenvolvimento por parte da doutrina e da jurisprudência. A forma célere e sem maiores formalidades com que foi estruturada a legitimação fundiária pode configurar, em determinados casos, indevida intervenção sobre o direito de propriedade. O problema é didaticamente exposto por Rosenvald (2017):

\begin{abstract}
Outrossim, ao versar sobre a aquisição originária de bens particulares na Reurb-S, não se encontra menção na lei ao direito de indenização por parte dos proprietários que perderão a sua titularidade originária, o que presume um aparente "confisco"que não coincide com as justificadas hipóteses constitucionais de desapropriaçãosanção pelo cultivo de psicotrópicos ou recurso ao trabalho escravo. Cria-se uma fuga da usucapião pela via oblíqua, eximindo-se dos requisitos do lapso temporal e do "animus domini". De fato, a legitimação fundiária de bens particulares mais se assemelha a uma desapropriação extrajudicial, na qual, ausentes balizas, o titular de um terreno invadido em 2016 será expropriado sem direito a indenização, caso a municipalidade considere que a ocupação estava consolidada! Fatalmente, vários questionamentos aportarão ao Supremo Tribunal Federal sobre a constitucionalidade do referido artigo 23, sobremaneira em sede da quebra da proporcionalidade na adequação abstrata realizada entre a nova modalidade de propriedade como acesso (direito à propriedade) e a garantia institucional do direito de propriedade como situação jurídica patrimonial, tutelada pela ordem econômica (art. 170, CF). Em outros termos, o que prevalece em termos de adequação principiológica no Estado Democrático de Direito? De um ângulo, a abertura ao estatuto da titularidade, pela concessão do mínimo existencial a quem antes era alijado de um piso patrimonial (segurança jurídica pelo prisma de efetivação de direitos fundamentais). De outro ângulo, a imposição de um limite as intervenções infraconstitucionais excessivas sobre o direito de propriedade, tutelando-se o patrimônio do titular formal (segurança jurídica sob o prisma da conservação de situações jurídicas lícitas).
\end{abstract}

A questão levantada pelo autor é precisa, porquanto sob o prisma do Estado Democrático de Direito haveria quebra da proporcionalidade na criação da legitimação

\footnotetext{
${ }^{12}$ Assim podemos considerá-la, pois a legitimação fundiária constitui interessante instrumento de emprego nas hipóteses onde houver: indefinição da titularidade do bem, se privada ou pública, ou mesmo, nos casos de propriedade particular, em especial, nas hipóteses onde o titular for desconhecido. Sua vantagem em relação à desapropriação nesses casos é bastante clara, haja vista sua maior celeridade (independe de intervenção judicial) e não implicar no dispêndio de elevados valores por parte do erário (indenização).
}

Revista Brasileira de Direito Civil em Perspectiva | e-ISSN: 2526-0243| Porto Alegre | v. 4 | n. 2

p. 102-119 | Jul/Dez. 2018 
fundiária, um choque entre a nova modalidade de acesso à propriedade e ao direito à habitação e a garantia institucional do direito de propriedade (art. $5^{\circ}$, XXII e art. 170, ambos da CF).

Parece inegável a colisão entre a garantia do direito à propriedade e a legitimação fundiária nos casos de Reurb, por isso será desenvolvida a análise da proporcionalidade do instrumento, como questionado por Rosenvald (2017) no tópico a seguir.

\section{EXAME DA PROPORCIONALIDADE DA LEGITIMAÇÃO FUNDIÁRIA}

Costa (2009) explica que a "proporcionalidade vem despertando, nos últimos tempos, o interesse da doutrina nacional. Isso porque se apresenta como um método racional para solucionar conflitos entre direitos fundamentais.".

O método da proporcionalidade decorre, segundo Alexy (2014), da natureza das normas princípio, "comandos de otimização". O autor separa as espécies de normas jurídicas em duas: as regras (mandamentos definitivos) e os princípios (mandamentos de otimização). Inclusive, para Alexy (2008), a distinção entre regras e princípios constitui uma das "colunas -mestras do edifício da teoria dos direitos fundamentais”, sobre sua importância afirma:

Essa distinção é a base da teoria da fundamentação no âmbito dos direitos fundamentais e uma chave para a solução de problemas centrais da dogmática dos direitos fundamentais. Sem ela não pode haver nem uma teoria adequada sobre as restrições a direitos fundamentais, nem uma doutrina satisfatória sobre colisões, nem uma teoria suficiente sobre o papel dos direitos fundamentais no sistema jurídico.

Alexy reconhece que ambas as espécies normativas, regras e princípios, constituem normas jurídicas e que igualmente podem ser formuladas mediante "operadores deônticos"13. Contudo, explica, que elas se diferenciam quanto à estrutura e aplicação.

As regras trazem a previsão da condição de fato (pressuposto fático) e a consequência jurídica, simplificando a ocorrência do fato jurídico (produção dos efeitos da norma) à adequação do fato à hipótese de incidência. Os princípios, por sua vez, não indicam pressuposto fático e tampouco seus efeitos jurídicos. Por isso, diferentemente das regras, que são aplicadas a partir da simples subsunção, os princípios têm aplicação pela ponderação,

\footnotetext{
${ }^{13}$ Operadores deônticos, resumidamente, seriam enunciados de obrigação, permissão e proibição.
} 
“identificando se se referem à situação em questão e avaliando o peso relativo que têm aquela situação em comparação com outros princípios incidentes" (COELHO, 2007).

Os conflitos entre regras duas regras é resolvido pela introdução, em uma das regras, de uma cláusula de exceção que elimine o conflito ou então pela invalidação de uma delas. De outro lado, a colisão entre princípios será resolvida pelo estabelecimento da precedência de um determinado princípio no caso específico, solução que não implica na exclusão do ordenamento do princípio não prevalente nem no afastamento por completo deste na situação em concreto, "o que ocorre é que um dos princípios tem precedência em face do outro sob determinadas condições" (ALEXY, 2008).

Em resumo, enquanto os conflitos entre regras resolvem-se na dimensão da validade, as colisões entre princípios tem na dimensão do peso a ordenação de sua precedência, conforme as circunstâncias fáticas e jurídicas do caso.

O autor, Alexy (2014), afirma que a construção dos direitos fundamentais como princípios, é aquela mais adequada para a compreensão da normatividade dos direitos fundamentais, notadamente quando se está diante das hipóteses de restrição à estes. Para ilustrar a afirmação utiliza-se dos seguintes exemplos: a) previsão de reserva de lei ordinária; e b) direitos fundamentais garantidos sem reserva.

Assevera que, se os direitos fundamentais forem interpretados como regras, ou seja, suscetíveis a regras de exceção, a previsão de reserva legislativa acabaria por resultar na desvinculação do legislador ao direito previsto, o que poderia resultar no esvaziamento do núcleo do direito. Quanto aos direitos fundamentais garantidos sem reserva, aduz que os problemas não são menores, utilizando o exemplo da liberdade religiosa, que na Lei Fundamental alemã não reconhece restrições. Assim sustenta:

No caso de subsunção isolada deveriam ser permitidos a opressão religiosa - se uma religião a exige - e experimentos com seres humanos, quando eles servem ao progresso científico. A saída de classificar essas ações não como ações religiosas ou atividades científicas contradiz o teor do texto. Quando se recorre, como razões para restrição, aos direitos à liberdade, à vida e à inviolabilidade corporal das pessoas atingidas, cai-se então inevitavelmente em uma ponderação. $\mathrm{O}$ postulado da interpretação sistemática arruína assim o modelo de regras. 
Após concluir sobre as vantagens da construção dos direitos fundamentais como princípios, afirma "o significado do caráter dos princípios resulta sobretudo de sua conexão com a máxima da proporcionalidade.” (ALEXY, 2014).

A proporcionalidade, para Alexy, constitui o procedimento próprio da ponderação. Este método de estrutura da ponderação é composto de três máximas, explica Coelho (2007):

A proporcionalidade é, segundo Alexy, informada por três máximas: (A) Adequação: a solução de uma colisão de princípios é adequada quando realiza o mandamento de pelo menos um dos princípios envolvidos. (B) Necessidade: a solução de uma colisão de princípios é necessária se realiza o mandamento de um dos princípios envolvidos com o menor sacrifício possível dos outros princípios envolvidos. (C) Proporcionalidade em sentido estrito: uma solução é proporcional se dá precedência ao princípio que, em vista das circunstâncias do caso concreto, tem de fato mais peso.

Com base nas colocações de Alexy (2008 e 2014), submeteremos o instrumento da legitimação fundiária ao método da proporcionalidade de forma a averiguar se a intervenção sobre o direito de propriedade gerada pelo artigo 23 da Lei 13.465/17 se adequa ou não à ordem constitucional brasileira, como questionou Rosenvald (2017).

Primeiramente, interessa ressaltar que a legitimação fundiária, por si, não encerra a regularização fundiária, pois esta deve abranger, além de providências jurídicas, medidas urbanísticas, ambientais e sociais (art. $9^{\circ}$ da Lei 13.465/17). Todavia, a concessão da propriedade encerra importante aspecto da Reurb, a titulação, um dos objetivos da regularização fundiária sobre o qual irá restringir-se este estudo. Sobre a importância deste aspecto leciona Rosenvald (2017):

Por outro lado, o legislador concebe a titulação como mecanismo capaz não apenas de resgatar para a legalidade urbana os possuidores e detentores de imóveis urbanos e rurais, como também de incrementar o mercado imobiliário e viabilizar a livre iniciativa de milhares de futuros empreendedores, na medida em que o registro da propriedade confere ao seu titular um ativo circulável hábil a proporcionar empréstimos a juros baixos, posto garantidos por hipotecas e propriedades fiduciárias. Nessa senda, Hernando de Soto assume com precisão que "o que falta aos pobres são sistemas legalmente integrados de propriedade que possam converter seus trabalhos e poupanças em capital". Realmente, conceder titulação em prol de uma massa de excluídos significa liquidar o "apartheid", converter apátridas em cidadãos e transformar capital morto (posse irregular) em capital vivo (ativos).

Feitos os esclarecimentos necessários, passa-se ao exame da proporcionalidade pela submissão às suas máximas. 
No que diz respeito ao exame das possibilidades fáticas, a legitimação fundiária satisfaz as duas máximas da adequação e da necessidade.

É inequívoco que as disposições do artigo 23 da Lei 13.465/17 são suficientes para a concessão da propriedade ${ }^{14}$, bem como asseguram a registrabilidade do título aquisitivo ${ }^{15}$.

Igual sorte se aplica no que diz respeito à máxima da necessidade, porquanto a legitimação fundiária combina três características não compartilhadas pelos demais instrumentos da Reurb aplicáveis de forma conjunta: a) forma de aquisição originária da propriedade; b) reconhecimento administrativo; c) não se condiciona ao depósito de indenização.

A aquisição originária consiste em uma vantagem frente à legitimação da posse (arts. 25-27), pois o desligamento do direito real adquirido a eventuais gravames pendentes sobre o imóvel $^{16}$ ocorre somente com a conversão da legitimação da posse em propriedade, o que acontecerá apenas se atendidos os requisitos da usucapião, situação nem sempre presente nas hipóteses de regularização, visto que a posse (condição para usucapião) não tem início enquanto não cessada a violência ou a clandestinidade ${ }^{17}$ (arts. 1.208 e 1.224 CC).

Por sua vez, o reconhecimento da propriedade nos casos de desapropriação administrativa depende de acordo ou processo judicial (art. 10 do DL 3.365/1941) além da indenização prévia (art. $5^{\circ}, \mathrm{XXIV}, \mathrm{CF}$ ), obrigação de indenizar que também condiciona a hipótese dos parágrafos $4^{\circ}$ e $5^{\circ}$ do artigo 1.228 do Código Civil (desapropriação judicial). Importante salientar que o óbice levantado a esses instrumentos não se restringe a pressuporem prévia intervenção judiciária, em verdade, a necessidade de indenização prévia

\footnotetext{
${ }^{14}$ Ver os comentários ao caput do artigo 23 feitos na seção dois, acima.

${ }^{15}$ Ver nesse sentido os dispostos nos artigos 42, 46 e 47 da Lei 13.465/17, pois estes dispositivos conformam verdadeira presunção absoluta de veracidade a incidir sobre as informações constantes da Certidão de Regularização Fundiária-CRF (art. 41) a vincular o juízo de admissibilidade do registrador imobiliário (qualificação registral), de forma a impedir a resistência do oficial de registro de imóveis no que diz respeito às informações do título expedido pelo poder público (presunção absoluta de atendimento ao princípio da especialidade).

${ }^{16}$ Sobre os efeitos da aquisição originária ver a citação a Loureiro (2011) feita na seção 2 acima.

${ }^{17}$ Esclarecedores sobre esse ponto os comentários de Loureiro (2011) ao artigo 1.208 do CC: "Sofreu a doutrina tradicional consistente crítica de Moreira Alves, para quem, com razão, a parte final do art. 1.208 não alude à posse injusta ou à posse inábil para usucapião, mas, em vez disso, é clara ao dispor que os atos violentos ou clandestinos não autorizam a aquisição da posse, enquanto não cessarem os ilícitos. Trata-se de mais um obstáculo que degrada uma situação aparentemente possessória, aviltando-a em detenção.".
}

Revista Brasileira de Direito Civil em Perspectiva | e-ISSN: 2526-0243| Porto Alegre | v. 4 | n. 2 |

p. $102-119$ | Jul/Dez. 2018 
constitui o principal impedimento fático à realização da Reurb, pois para grande parte dos Municípios brasileiros a escassez de recursos é uma realidade constante.

Portanto, resta a análise da possibilidade jurídica, a máxima parcial da proporcionalidade em sentido estrito. Para esta averiguação é necessário estremar duas situações distintas, a legitimação fundiária nas hipóteses de Reurb-E e nas hipóteses de Reurb-S.

Na Reurb-E entendemos que a aplicação do artigo 23 da Lei 13.465/17 implica em real ofensa à garantia institucional do direito de propriedade, como questionou Rosenvald (2017), pois a possibilidade de reconhecimento administrativo da propriedade, somada a desnecessidade de comprovação de requisitos temporais ou comprovação da justiça ou boa-fé da posse acabam por encerrar intervenção excessiva sobre o direito fundamental à propriedade (art. $5^{\circ}, \mathrm{XXII}, \mathrm{CF}$ ), posto que neste caso o choque será entre a propriedade do titular registrado em cartório contra o suposto direito de aquisição de propriedade do possuidor/detentor.

Por outro lado, no que diz respeito à Reurb-S, conclusão distinta se impõe. Isso porque, na Reurb-S, salta aos olhos a incidência do direito fundamental à moradia (art. $6^{\circ}$ da $\mathrm{CF}$ ). Este direito se manifesta pela necessária submissão do beneficiário a um duplo filtro de admissão: i) adequação aos critérios de baixa renda indicados pelo Município (art. 13, I), o que denota a presunção de vulnerabilidade social; e ii) enquadramento nas condicionantes do $\S 1^{\circ}$ do art. 23 que evidenciam a presença do direito à moradia, as quais exigem que "o beneficiário não seja concessionário, foreiro ou proprietário de imóvel urbano ou rural" (art. $\left.23, \S 1^{\circ}, I\right)$. Tais requisitos denotam uma situação fática e jurídica distinta daquela sobre a qual nos deparamos nas hipóteses de Reurb-E, por isso conclui-se que a legitimação fundiária sobre bens particulares constitui instrumento idôneo nas hipóteses de Reurb-S.

\section{CONSIDERAÇÕES FINAIS}

A legitimação fundiária surge como um importante instrumento a serviço do poder público na realização da regularização fundiária, sendo uma das novidades mais significativas e polêmicas da Lei 13.465/17.

Revista Brasileira de Direito Civil em Perspectiva | e-ISSN: 2526-0243| Porto Alegre | v. 4 | n. 2 |

p. $109-112$ | Jul/Dez. 2018 
É certo que a estrutura legislativa diferenciada do artigo 23 da Lei 13.465/17, apenas se justifica ante a preexistência de interesses coletivamente relevantes que justificam e estimulam as políticas de regularização fundiária: a) promoção da segurança da titularidade cuja finalidade é fomentar o mercado de terras nacional; e b) promover o direito à moradia digna (art. $6^{\circ}$ da $\left.\mathrm{CF}\right)$ a que grande parte da população brasileira se vê excluída.

A partir desse duplo escopo da Lei 13.465/17, econômico e social, deve o intérprete aplicar os instrumentos dispostos no artigo 15. Pois, a depender da finalidade prestigiada haverá um instrumento correspondente.

O exame da proporcionalidade a que foi submetido o artigo 23 da Lei 13.465/17 buscou extrair uma interpretação do dispositivo em conformidade com a Constituição Federal de 1988, de forma a indicar uma aplicação da Lei 13.465/17 sob a luz dos direitos fundamentais. Esta proposta segue no sentido de evitar que possíveis impugnações futuras à Lei 13.465/17, em sede de controle concreto ou abstrato de constitucionalidade prejudiquem as políticas de regularização em andamento e futuras, bem como evitar a provável responsabilização do poder público caso entendam os Tribunais pela ilegitimidade da aplicação da legitimação fundiária nesses casos (art. 37, § 6, $\mathrm{CF}$ ).

Por fim, a conclusão acerca da inconstitucionalidade do emprego da legitimação fundiária sobre áreas particulares nas hipóteses de Reurb-E, não implica na indicação de uma omissão legislativa nesta hipótese, mas, somente, induz à necessidade do emprego de outros instrumentos, tais como a legitimação da posse (arts. 25-27) e a usucapião extrajudicial (art. 216-A da Lei 6.015); os quais prescindem de intervenção judicial, ensejam a aquisição do bem de forma livre e desembaraçada (aquisição originária da propriedade), além de não se condicionarem à prévia indenização.

\section{REFERÊNCIAS}

ALEXY, Robert. Teoria dos direitos fundamentais. Trad. Virgílio Afonso da Silva. Editora Malheiros. São Paulo. 2008.

ALEXY, Robert. Teoria discursiva do Direito. Tradução, organização e estudo introdutório Alexandre Travessoni Gomes Trivisonno. Forense. $2^{\text {a }}$ edição. Rio de Janeiro. 2014.

Revista Brasileira de Direito Civil em Perspectiva | e-ISSN: 2526-0243| Porto Alegre | v. 4 | n. 2 |

p. 102-119 | Jul/Dez. 2018 
PELUSO, Cesar. Código CIVI COMENTADO. Organização Cezar Peluso. Autores Francisco Eduardo Loureiro et al. Editora Manole. 5 edição. São Paulo. Ano 2011.

COELHO, André. Alexy e sua teoria dos princípios. Disponível em: $<$ http://aquitemfilosofiasim.blogspot.com.br/2007/06/alexy-e-sua-teoria-dosprincipios.html>. Acesso em: 18 Jan. 2018.

COSTA, Roberta Pereira Negrão. PROPORCIONALIDADE. UMA CLARIFICAÇÃo DO CONCEITO. REVISTA DA AGU, [S.1.], dec. 2009. ISSN 2525-328X. Disponível em: <http://seer.agu.gov.br/index.php/AGU/article/view/256>. Acesso em: 18 Jan. 2018.

DE SOTO, Hernando. O mistério do capital. Rio de Janeiro: Record, 2001.

FARIAS, Cristiano Cahves de e ROSENVALD, Nelson. Curso de Direito Civil - Direitos Reais. Volume 5. $8^{\text {a }}$ edição. revista, ampliada e atualizada. Salvador-BA. Editora Juspodivm. 2012.

FERNANDES, Edésio. Desafios da regularização fundiária de assentamentos informais consolidados em áreas urbanas. In: Fórum de Direito Urbano e Ambiental, Belo Horizonte, v. 9, n. 49, jan. 2010. Disponível em: <http://bdjur.stj.jus.br/jspui/bitstream/2011/63990/desafios_regularizacao_fundiaria_fernande s.pdf>. Acesso em 03 jul. 2017.

FAO/SEAD. Governança de terras: da teoria à realidade brasileira. Brasília, 2017.

MARICATO, Ermínia. O Estatuto da cidade periférica. In: O Estatuto da Cidade: Comentado. São Paulo: Ministério das Cidades/Aliança das Cidades, 2010.

ROLNIK, Raquel. A construção de uma política fundiária e de planejamento urbano para o país - Avanços e desafios. In: IPEA: Políticas sociais - acompanhamento e análise. N. 12 , fev. 2006.2 Disponível em: 〈http://ipea.gov.br/agencia/images/stories/pdfs/politicas_sociais/ensaio1_raquel12.pdf>.

Acesso em 03/08/2017.

ROSENVALD, Nelson. A legitimação fundiária - uma polêmica inovação. Disponível em: <https://www.nelsonrosenvald.info/single-post/2017/12/20/A-Legitima\%C3\%A7\%C3\%A3ofundi $\% \mathrm{C} 3 \% \mathrm{~A} 1$ ria- $\% \mathrm{E} 2 \% 80 \% 93-$ umapol\%C3AAmica-inova\%C3\%A7\%C3\%A30>. Acesso em: 17 Jan. 2018.

MELO, Marcelo Augusto Santana de. Legitimação Fundiária: Natureza jurídica. Disponível em: https://marcelommmelo.com/2017/11/21/legitimacao-fundiaria-naturezajuridica/ Acesso em 04/12/2017.

VANIN, F., HERMANY, R. Análise crítica das mudanças promovidas pela Medida Provisória n. 759/2016 na regularização fundiária do Brasil / Critical analysis of changes promoted by Provisional Measure n. 759/2016 in the land regulation in Brazil. Revista de Direito da Cidade, Local de publicação (editar no plugin de tradução o arquivo da citação

Revista Brasileira de Direito Civil em Perspectiva | e-ISSN: 2526-0243| Porto Alegre | v. 4 | n. 2 |

p. $109-112$ | Jul/Dez. 2018 
ABNT), 9, abr. 2017. Disponível em: < publicacoes.uerj.br/index.php/rdc/article/view/27233 > . Acesso em: 18 Jan. 2018 